\title{
SISTEM INFORMASI GEOGRAFIS PEMETAAN LOKASI BENCANA ALAM DI SUMATERA UTARA BERBASIS WEB
}

\author{
Yustria Handika Siregar ${ }^{1}$, Mardiana Nainggolan ${ }^{2}$ \\ ${ }^{1,2,3}$ Fakultas Teknik Jurusan Teknik Informatika Universitas Asahan \\ Jl. Jend Ahmad Yani Kisaran Sumatera Utara \\ ${ }^{1}$ yustriahandikasiregaregmail.com, 2mardiananainggolan4@gmail.com
}

\begin{abstract}
Abstrak - Perkembangan di bidang teknologi informasi, khususnya sistem informasi telah membawa kemudahan yang menjanjikan sebuah efisiensi kerja. Misalnya Sistem informasi geogfrafis adalah alat dengan sistem komputer yang digunakan untuk memetakan kondisi dan peristiwa yang terjadi di muka bumi merupakan suatu sistem yang bersifat membantu memberikan serta menyajikan informasi yang dibutuhkan oleh pengguna. Adanya berkembangnya terutama pada aspek kebutuhan linkungan agar menangulangi atau mengurangi dampak bencana yang ada di daerah sumatera, serta dengan perbaikan kinerja dari BPBD, maka perlu adanya suatu sistem informasi berbasis GIS yang dapat memperlihatkan titik bencana BPBD yang sudah ada di Sumatera Utara. Dengan adanya informasi peta terutama dalam sistem web, diharapkan dapat memberikan informasi yang cepat dan akurat, terlebih mengetahui titik lokasi bencana secara tepat. sehingga memudahkan pekerjaan petugas dalam memberikan informasi bencana pada kantor pusat.
\end{abstract}

Kata Kunci - Sistem Informasi Geografis, Pemetaan, Web.

\section{PENDAHULUAN}

Pada era modern seperti saat ini, komputer sangat banyak membantu kehidupan masyarakat mulai dari pekerja, pelajar dan masyarakat umum. Kemunculan komputer menjadi titik balik dari sebuah sistem yang telah berjalan selama ini secara manual. Jika dahulu mengerjakan sesuatu secara manual dianggap memerlukan banyak waktu untuk menyiapkan satu jenis pekerjaan, tetapi saat ini dengan bantuan komputer banyak jenis pekerjaan yang dapat dikerjakan sekaligus tanpa memakan terlalu banyak waktu.

Dalam mendukung perkembangan teknologi yang terus berkembang, dimana komputer bukanlah barang baru, melainkan suatu media yang sangat membantu sekaligus dibutuhkan peranannya bagi manusia sebagai penggunanya. Komputer dianggap dapat memberikan.

solusi kepada manusia dalam pengerjaan suatu masalah. Berkembangnya suatu teknologi disekitar kita dapat dijadikan tolak ukur terhadap kemajuan suatu bangsa. Di Indonesia perkembangan teknologi dikategorikan tidak terlalu cepat dan efisien. Negara Kesatuan Republik Indonesia memiliki wilayah yang luas dan terletak digaris khatulistiwa pada posisi silang antara dua benua dan dua samudra dengan kondisi alam yang memiliki berbagai keunggulan, namun di pihak lain posisinya berada dalam wilayah yang memiliki kondisi gegrafis, geologis, hidrologis dan demografis yang rawan terhadap terjadinya bencana dengan frekwensi yang cukup tinggi, sehingga memerlukan penanganan yang sistematis, terpadu dan terkoordinasi. Potensi terjadinya bencana alam yang sering terjadi di wilayah Sumatera Utara adalah tanah gunung meletus, gempa bumi, banjir, kebakaran dan topan. Mengingat kejadian bencana alam di daerah Sumatera Utara beberapa akhir-akhir ini seperti tanah longsor, banjir, sungai meluap dan gunung meletus yang terjadi dibeberapa tempat. Dan juga dilihat dari karakteristik daerah Sumatera Utara maka dilakukan pemetaan daerah risiko bencana alam dengan pemanfaatan Sistem Informasi Geografis (GIS) yang bertujuan untuk memberikan informasi lokasi-lokasi yang memiliki risiko bencana alam.

Untuk membantu mengurangi bencana alam dan dampaknya, diperlukan sebuah sistem yang mampu menentukan daerah yang termasuk daerah sering terjadi bencana alam untuk mencegah agar tidak ada korban jiwa atau kerugian. Dengan adanya sistem ini diharapkan mampu membantu pihak pemerintah khususnya Badan Penanggulangan Bencana Daerah (BPBD) untuk melakukan tindakan pencegahan bencana alam. Berdasarkan latar belakang masalah tersebut, maka penulis mengajukan judul "Sistem Informasi Geografis Pemetaan Lokasi Bencana Alam di Sumatera Utara Berbasis Web".

\section{A. Pengertian Sistem}

\section{LANDASAN TEORI}

Menurut Jogiyanto (1999:1), sistem adalah suatu jaringan kerja dari prosedur-prosedur yang saling berhubungan, berkumpul bersama-sama untuk melakukan suatu kegiatan atau menyelesaikan suatu sasaran tertentu (dalam Mochamad Rendy Riskianto Widodo, Et Al, 2016).

Menurut Sommerville (2003), sistem adalah sekumpulan komponen yang saling berhubungan dan bekerja sama untuk mencapai suatu tujuan (dalam Isti Qomariyah Kumala Dewi, Et Al, 2016).

$B$. Pengertian Informasi

Menurut Muhammad Dedi Irawan (2017), informasi adalah data yang di olah menjadi bentuk yang lebih berguna dan lebih berarti bagi penerimanya". Kualitas dari suatu informasi (quality of information) tergantung dari tiga hal, yaitu informasi harus akurat (accurate), tepat waktu (timeliness), dan relevan (relevance).

Menurut Jogiyanto HM (1999:692), informasi dapat didefinisikan sebagai hasil dari pengolahan data 
dalam suatu bentuk yang lebih berguna dan lebih berarti bagi penerimanya yang menggambarkan suatu kejadian-kejadian (event) yang nyata (fact) yang digunakan untuk pengambilan keputusan (dalam Mochamad Rendy Riskianto Widodo, Et Al, 2016).

C. Pengertian Sistem Informasi

Menurut Lani Sidharta (1995:28), sistem informasi adalah suatu sistem buatan manusia yang berisi serangkaian terpadu komponen-komponen manual dan komponen-komponen terkomputerisasi yang bertujuan untuk mengumpulkan data, mengolah data, dan menghasilkan informasi bagi pengguna (dalam Mochamad Rendy Riskianto Widodo, Et Al, 2016).

D. Pengertian Sistem informasi geografis

Menurut Aini (2011), Sistem Informasi Geografis (SIG) atau Geographic Information Sistem (GIS), merupakan suatu sistem informasi yang berbasis komputer, dirancang untuk bekerja dengan menggunakan data yang memiliki informasi spasial (bereferensi keruangan). Sistem ini mengcapture, mengecek, mengintegrasikan, memanipulasi, menganalia,dan menampilkan data yang secara spasial merefrensikan kepada kondisi bumi. Teknologi SIG mengintegrasikan operasi-operasi umum database, seperti query dan analisa statistik, dengan kemampuan visualisasi dan analisa yang unik yang dimiliki oleh pemetaan. Kemampuan inilah yang membedakan SIG dengan sistem informasi lainnya yang membuatnya menjadi berguna berbagai kalangan untuk menjelaskan kejadian, merencanakan strategi, dan memprediksi apa yang terjadi (dalam Dede Wira Trise Putra, Et Al, 2016).

\section{E. UML}

Menurut Fowler (dalam Diah Puspitasari, 2015), Unified Modeling Language (UML) adalah keluarga notasi grafis yang didukung oleh meta-model tunggal, yang membantu pendepenelitianan dan desain sistem perangkat lunak, khususnya sistem yang dibangun menggunakan Pemrograman Berorientasi Objek (PBO). Definisi ini merupakan definisi yang sederhana. Pada kenyataannya, pendapat orang-orang tentang UML berbeda satu sama lain. Hal ini dikarenakan oleh sejarahnya sendiri dan oleh perbedaan persepsi tentang apa yang membuat sebuah proses rancang-bangun perangkat lunak efektif.

\section{F. $\quad$ PHP (Hypertext Preprocessor)}

Menurut Ridwan Sanjaya, 2009 ,PHP merupakan bahasa scripting yang berjalan di sisi server (server-slide). Semua perintah yang ditulis akan dieksekusi oleh server dan hasil jadinya dapat dilihat melalui browser. Saat ini PHP versi 4 sudah di-release di psaran, mengikuti jejak kesuksesan versi sebelumnya, PHP 3. Selain dapat digunakan untuk berbagai sistem operasi, koneksi database yang sangat mudah menyebabkan bahsa scripting ini digemari para programmer web. Beberapa perintah PHP yang dipelajari sebatas pada perintah untuk menampilkan tag-tag wml, akses database MySQL dan pengiriman email (dalam Gellysa Urva, Helmi Fauzi Siregar, 2015).

Menurut Bimo Sunarfrihantono, ST. (2002:9), PHP adalah bahasa server-side scripting yang menyatu dengan HTML untuk membuat halaman web yang dinamis. Maksud dari server-side scripting adalah sintaks dan perintah-perintah yang diberikan akan sepenuhnya akan dijalankan dalam system (dalam Mochamad Rendy Riskianto Widodo, Et Al, 2016).

Menurut Nugroho (2004), PHP merupakan bahasa standar yang digunakan dalam dunia situs web. PHP adalah bahasa program yang berbentuk skrip yang diletakkan di dalam server web. Dalam hal ini, aplikasi pada umumnya akan memberikan hasil pada perambah web, tetapi prosesnya secara keseluruhan dijalankan dan dikerjakan di server web (dalam Isti Qomariyah Kumala Dewi, Et Al, 2016).

Menurut Peranginangin (2006), program web dengan server side salah satunya adalah PHP yang akan digunakan sebagai bahasa pemrograman web dalam aplikasi ini. PHP adalah singkatan dari Personal Home Page yang merupakan bahasa standar yang digunakan dalam dunia website. PHP adalah bahasa pemrogaman yang berbentuk script yang diletakkan di dalam Hypertext Preeprocessor Hal ini merupakan bahasa yang hanya dapat berjalan pada server yang pada sisi server disebut server side, berbeda dengan mesin maya java yang mengeksekusi program pada sisi klien atau client-server (dalam Domisia Eka Nur Imani1, Et $\mathrm{Al}, 2017)$.

Menurut Abdul Kadir (2002:98), PHP adalah bahasa pemrograman web atau scripting language yang dijalankan diserver. PHP dibuat pertama kali oleh Rasmus Lerdorf, yang pada awalnya dibuat untuk menghitung jumlah pengunjung pada homepagenya. Pada waktu itu PHP bernama FI (Form Interpreter). Pada saat tersebut PHP adalah sekumpulan script yang digunakan untuk mengolah data form dari web. Perkembangan selanjutnya adalah Rasmus melepaskan kode sumber tersebut dan menamakannya PHP/FI, pada saat tersebut kepanjangan dari PHP/FI adalah Personal Home Page/Form Interpreter. Pelepasan kode sumber ini menjadi open source, maka banyak programmer yang tertarik untuk ikut mengembangkan PHP. Pada tahun 1997 sebuah perusahaan bernama Zend, menulis ulang interpreter PHP mejadi lebih bersih, lebih baik dan lebih cepat. Kemudian pada Juni 1998 perusahaan tersebut merilis interpreter baru untuk PHP dan meresmikan nama rilis tersebut menjadi PHP 3.0. Pada pertengahan tahun 1999, Zend merilis interpreter PHP baru dan rilis tersebut dikenal dengan PHP 4.0. PHP 4.0 adalah versi PHP yang paling banyak dipakai. Versi ini banyak dipakai sebab versi ini mampu dipakai untuk membangun aplikasi web kompleks tetapi tetap memiliki kecepatan proses dan stabilitas yang tinggi. Pada Juni 2004 Zend merilis PHP 5.0. Versi ini adalah versi mutakhir dari PHP. Dalam versi ini, inti dari interpreter PHP mengalami perubahan besar. Dalam versi ini juga dikenalkan model pemrograman berorientasi objek baru untuk menjawab perkembangan bahasa pemrograman kearah 
pemrograman berorientasi objek. Hal yang menarik yang didukung oleh PHP adalah kenyataan bahwa PHP bisa digunakan untuk mengakses berbagai macam database seperti Access, Oracle, MySQL, dan lain-lain (dalam Fajar Hariadi, 2013).

\section{G. MYSQL}

Menurut Bimo Sunarfrihantono, ST. (2002:13), MySQL adalah multiuser database yang menggunakan bahasa Structured Query Language (SQL). MySQL dalam operasi client server melibatkan server daemon MySQL disisi server dan berbagai macam program serta library yang berjalan disisi client. MySQL mampu menangani data yang cukup besar. Perusahaan yang mengembangkan MySQL yaitu TEX, mengaku mampu menyimpan data lebih dari 40 database, 10.000 tabel dan sekitar 7.000.000 baris totalnya kurang lebih 100 Gigabyte data (dalam Mochamad Rendy Riskianto Widodo, Et $\mathrm{Al}, 2016)$.

\section{H. Pemogramana Berbasis Web}

Menurut Abdul Kadir (2013:25), Web berasal dari kata Bahasa Inggris yang bila diterjemahkan dalam Bahasa Indonesia berarti "Jaring Laba-Laba". Hampir sama dengan arti dari kata web itu sendiri, web telah membentang ke seluruh penjuru dunia. Tidak hanya terbatas pada lembaga-lembaga penelitian yang ingin memublikasikan hasil riset, tetapi juga telah banyak digunakan oleh perusahaan bisnis yang ingin mengiklankan produk atau untuk melakukan transaksi bisnisnya (dalam Mochamad Rendy Riskianto Widodo, Et Al, 2016).

Menurut Krisianto (2014:1), internet adalah salah satu bentuk media komunikasi dan informasi interaktif. Wujud internet adalah jaringan komputer yang terhubung di seluruh dunia. Internet digunakan untuk mengirim informasi antar komputer di seluruh dunia.Internet diartikan sebagai "The global public Transmission Control Protocol/Internet Protocol (TCP/IP) internetwork". Jadi Internet adalah gabungan dari seluruh komputer didunia yang di satukan oleh sebuah "bahasa" yang sama, adapun bahasa yang dimaksud adalah Transmission Control Protokol/Internet Protokol (dalam Diah Puspitasari, 2015).

\section{METODE PENELITIAN}

\section{A. Rancangan Penelitian}

Bab ini membahas metode yang digunakan pada penelitian "Sistem Informasi Geografis Pemetaan Lokasi Bencana Alam di Sumatera Utara Berbasis Web", menjelaskan terkait pengumpulan data, analisa sistem, desain, implementasi dan laporan.

Untuk lebih jelas dalam memahami alur penelitian, dapat dilihat pada gambar 3.1 berikut.

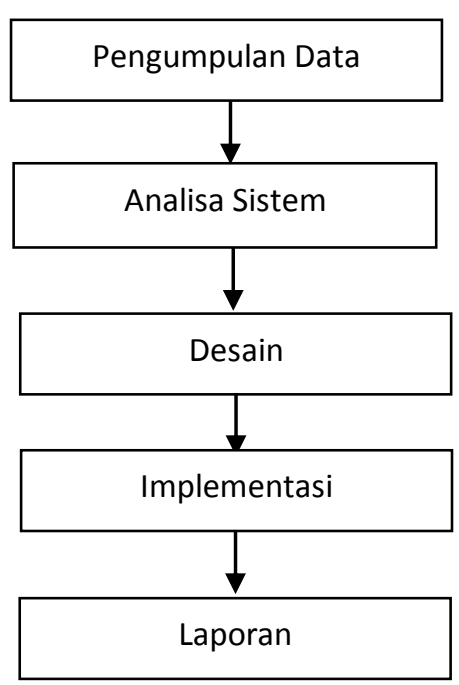

Gambar 1 Kerangka Kerja Penelitian

\section{B. Objek Penelitian}

Objek penelitian merupakan permasalahan yang diteliti. Objek dari penelitian ini adalah bagaimana membangun sebuah aplikasi yang dapat menampilkan terjadinya tempat bencana alam. Penelitian ini berdasarkan tempat dan waktu seperti sistem yang dibutuhkan dalam pembuatan sistem informasi geografis pemetaan lokasi bencana alam di Sumatera Utara berbasis web.

\section{Defenisi Operasional Variabel}

Variabel yang digunakan pada penelitian adalah unsur yang berkaitan dengan perancangan aplikasi menggunakan pemograman berbasis web. Adapun variabel yang digunakan dalam penelitian ini adalah sebagai berikut:

1. Variabel lokasi bencana alam.

2. Variabel peristiwa bencana alam.

D. Sumber data

Adapun jenis data yang digunakan dalam penelitian ini adalah sebagai berikut:

1. Data Primer

Data primer yang diperoleh secara langsung dari data-data Badan Penanggulangan Bencana Daerah (BPBD) yang terdapat pada tepatnya di Sumatera Utara.

2. Data Sekunder

Data sekunder diperlukan untuk mendukung hasil penelitian. Data tersebut berasal dari jurnal, internet dan berbagai sumber lain yang berhubungan dengan masalah penelitian sehingga memudahkan dalam penyelesaian masalah. 


\section{E. Metode Analisa Sistem}

Metode analisa sistem pada penelitian ini menggunakan metode deskriptif, yaitu dapat diartikan sebagai prosedur pemecahan masalah yang diselidiki dengan menggambarkan keadaan subjek atau objek dalam penelitian yang dapat berupa orang, lembaga, masyarakat dan yang lainnya yang pada saat sekarang berdasarkan fakta-fakta yang tampak atau apa adanya.

Metode analisa sistem yang digunakan penulis dalam pembuatan sistem informasi geografis ini adalah dengan cara menganalisis data yang berhasil dikumpulkan untuk mencapai suatu kesimpulan, yaitu:

\section{Analisa Sistem}

Di dalam laporan tugas akhir ini dibuat sebuah aplikasi yang berfungsi untuk mempermudah pencarian lokasi bencana alam.

2. Analisa Input Sistem

Pada form input sistem menampilkan interface dari form inputan lokasi. Dimana pada bagian input sistem dijelaskan bahwa form tersebut digunakan untuk menginput data atau informasi yang berhubungan dengan bencana alam.

3. Analisa Process Sistem

Dimana pada process sistem ini akan menampilkan menu utama, menu login dan menu utama.

4. Analisa Output Sistem

Pada bagian output dimana pada bagian ini dapat menampilkan hasil informasi titik lokasi bencana alam.

\section{ANALISA DAN PEMBAHASAN}

\section{A. Analisis}

Dalam melakukan pembangunan aplikasi ini terdapat beberapa masalah dan faktor penting yang perlu diperhatikan yaitu mengenai permasalahan bagaimana pengguna dapat memetakan daerah yang sedang terkena bencana melalui aplikasi sistem informasi geografis becana alam. Hasil analisa ini akan dijadikan sebagian acuan dalam pembangunan aplikasi.

1. Analisa Kebutuhan Perangkat Keras (Hardware) Adapun alat pendukung yang digunakan dalam pembuatan aplikasi ini adalah sebagai berikut :

1. Perangkat Keras

Dalam merancang aplikasi ini dibutuhkan beberapa perangkat keras yang digunakan agar hasilnya dapat maksimal. Dalam penelitian ini penulis menggunakan laptop untuk merancang dan menjalankan aplikasi yang telah dibuat atau dikembangkan. Adapun spesifikasi hardware yang digunakan penulis sebagai berikut:

1. Sistem Operasi : Windows 2007.

2. Prosesor : Intel(R) Celeron(R) CPU 1000M @ $1.80 \mathrm{GHz}$.

3. Harddisk : $210 \mathrm{~GB}$.

4. Memory : 2 GB.

5. Dimensi Layar : 16 inchi.

\section{Perangkat Lunak}

Dalam merancang aplikasi ini dibutuhkan beberapa software yang digunakan agar hasilnya dapat maksimal. Berikut software yang digunakan :

1.Bahasa Pemrograman Web

Dalam hal ini digunakan bahasa pemograman PHP dan MySQL.

2. Sistem Operasi

Untuk pengguna sistem operasi menggunakan windows 2007.

3. Appserv

Untuk memudahkan dalam pengembangan aplikasi, maka digunakan Appserv karena memiliki beberapa fasilitas yang diperlukan dalam pembangunan perangkat lunak.

B. Use Case Diagram

1. Use Case

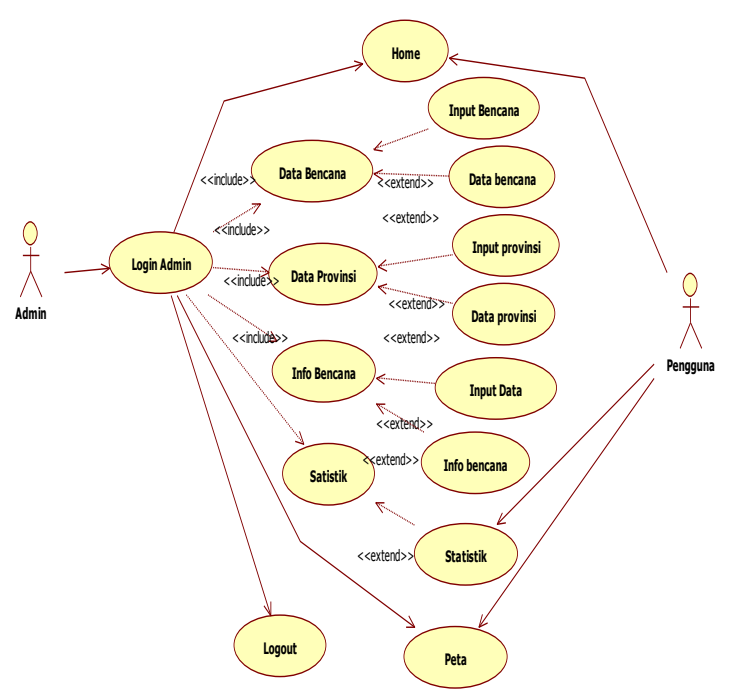

Gambar 2 Use Case

\section{Class Diagram}

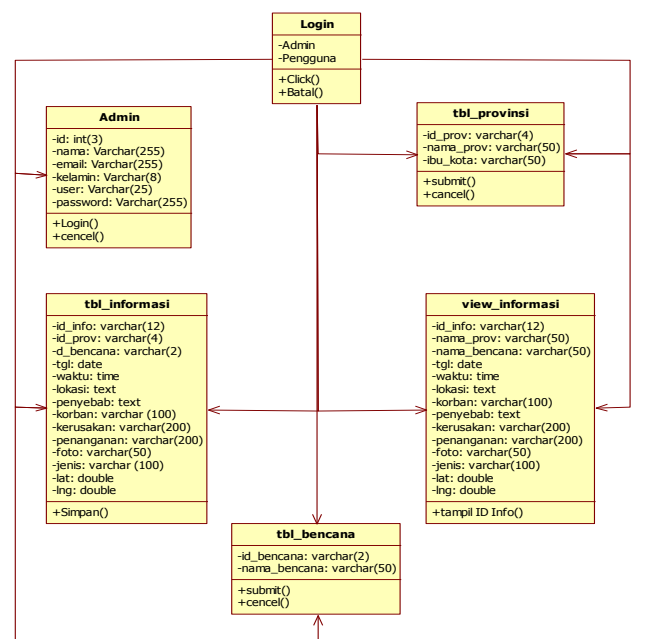

Gambar 3 Class Diagram

\section{Activity Diagram}

Activity Diagram menggambarkan aktivitas dari sebuah sistem atau proses bisnis atau menu yang 
ada pada perangkat lunak. Adapun activity diagram yang diusulkan adalah sebagai berikut :

1.Activity Diagram Admin

1. Activity Diagram Menu Utama

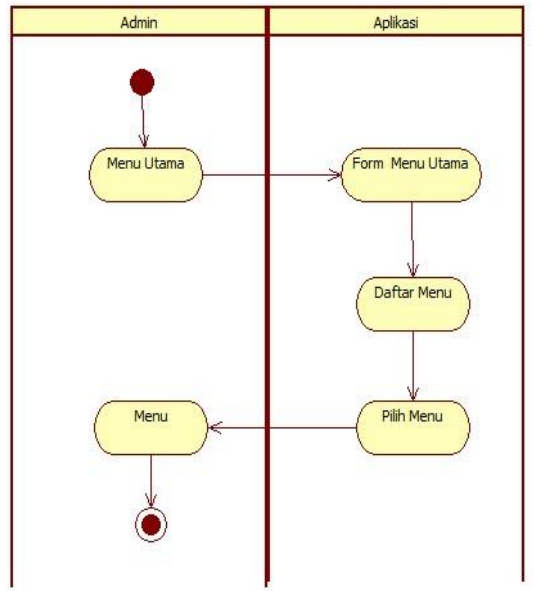

Gambar 4 Activity Diagram Menu Utama

\section{E. Sequence Diagram}

Sequence diagram merupakan diagram yang menggambarkan pola hubungan diantara sekumpulan objek yang saling mempengaruhi menurut urutan waktu. Sequence diagram pada aplikasi ini adalah sebagai berikut :

\section{Sequence Diagram}

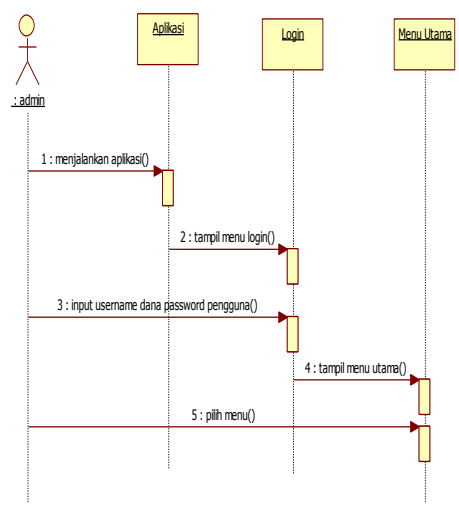

Gambar 5 Sequence Diagram Menu Login

\section{F. Statechart Diagram}

Statechart Diagram menggambarkan transisi dan perubahan keadaan (dari satu state ke state lainnya) suatu objek pada sistem sebagai akibat dari stimuli yang diterima. Statechart Diagram pada aplikasi ini adalah sebagai berikut :

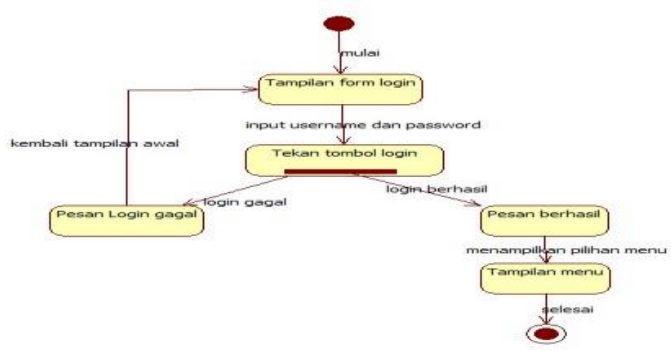

Gambar 6 Statechart Diagram Menu Login
G. Collaboration Diagram

Collaboration Diagram juga menggambarkan interaksi antar objek seperti sequence diagram, tetapi lebih menekankan pada peran masing-masing objek dan bukan pada waktu penyampaian message. Setiap message memiliki sequence number, di mana message dari level tertinggi memiliki nomor 1. Messages dari level yang sama memiliki prefiks yang sama. Collaboration Diagram pada aplikasi ini adalah sebagai berikut :

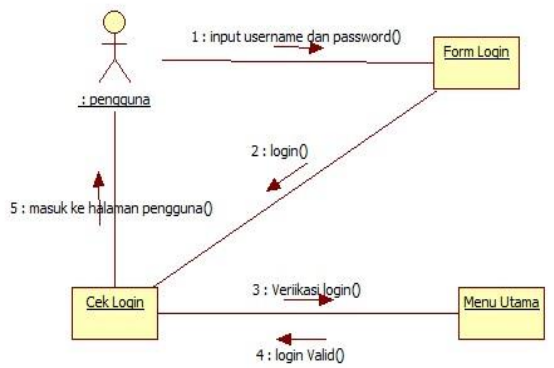

Gambar 7 Collaboration Diagram Menu Login

H. Implementasi Tampilan Program

1. Tampilan Menu Utama Pengguna

Menu Utama merupakan tampilan utama setelah aplikasi dijalankan, di dalam menu utama ini terdapat menu beranda, untuk menuju ke menu-menu yang lain.

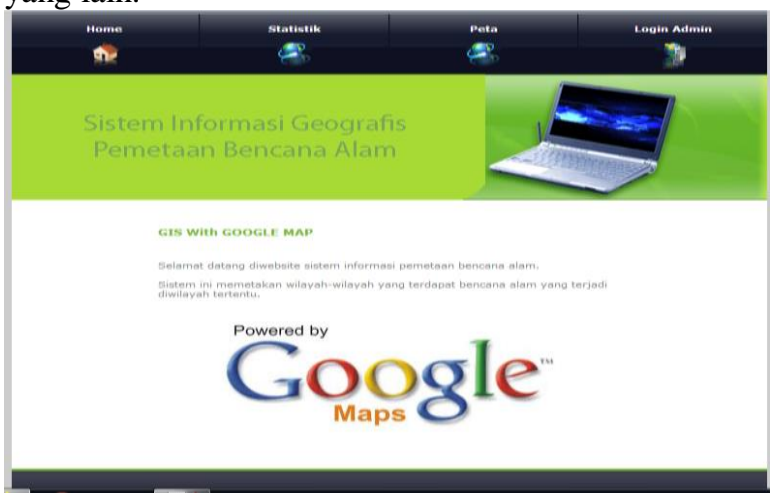

Gambar 8 Tampilan Menu Utama Pengguna

2. Tampilan Menu Admin

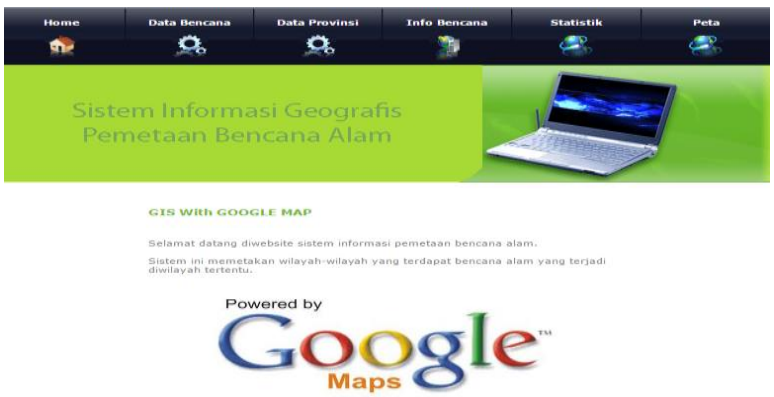

Gambar 9 Tampilan Menu Admin 


\section{PENUTUP}

\section{A. Kesimpulan}

Dari penjelasan yang telah diuraikan dapat ditarik kesimpulan mengenai hal-hal dasar sangat erat kaitannya dengan sistem informasi geografis pemetaan bencana alam di Sumatera Utara berbasis WEB maka dapat disimpulkan sebagai berikut :

1.Penelitian ini menghasilkan web sistem informasi geografis pemetaan bencana alam yang berfungsi menampilkan informasi bencana yang ada di Sumatera Utara dengan menu statistik, peta dan menu login.

2.Sistem informasi yang telah dibuat dapat dipahami dan sangat mempermudah bagi pengguna untuk mengetahui bencana alam yang ada di Sumatera Utara.

3.Data yang digunakan pada sistem, yaitu menggunakan sistem Unified Modelling Language (UML). Dengan menggunakan UML para pengguna lebih mudah dalam menganalisa dan mendesain suatu sistem.

\section{B. Saran}

Dari pembahasan pada bab-bab sebelumnya Berdasarkan pembahasan yang telah penulis lakukan, penulis mengemukakan saran, yaitu sebagai berikut :

1.Disarankan sebaiknya di kedepannya dapat dikembangkan lagi seperti menggunakan mobile android.

2.Sebaiknya data dan informasi yang ada juga dilakukan secara komputerisasi dan manual untuk mencegah hal-hal yang tidak diinginkan.

3.Perlu data yang lebih lengkap dan lebih rinci mengenai jumlah bencana pertahun.

\section{DAFTAR PUSTAKA}

[1] Aziz, M., \& Pujiono, S., Sistem Informasi Geografis Berbasis Desktop Dan Web, .

[2] Abdul, Kadir, Pengenalan Sistem Informasi, Penerbit Andi, Yogyakarta, 2003.

[3] Bunafit Nugroho (2008), Aplikasi Pemrograman Web Dinamis Dengan PHP \& MySQL, Gava Media, Yogyakarta.

[4] Nurdin, Amin Munthoha, 2017. "Sistem Pendeteksi Kemiripan Judul Penelitian Menggunakan Algoritma Winnowing". Jurnal Nasional Informatika dan Teknologi Jaringan. Vol 2 No 1. 90-97.

[5] Muhammad Dedi Irawan, Laila Hasni, 2017. "Sistem Penggajian Karyawan Pada Lkp Grace Education Center". Jurnal Teknologi Informasi Vol.1, No.2. E-ISSN 2615-2738 No 1. 125-136.

[6] Dede Wira Trise Putra, Kadris, (2016). "Sistem Informasi Geografis Pemetaan Sarana Prasarana Departemen Agama Kota Sungai Penuh Berbasis Web", Jurnal Teknoif, Vol. 4 No. 2. 76-81.

[7] Fowler, Martin. 2005. UML Distilled Edisi 3, Yogyakarta: Andi.
[8] Gellysa Urva, Helmi Fauzi Siregar, (2015). "Pemodelan UML E-Marketing Minyak Goreng", Jurnal Teknologi dan Sistem Informasi, Vol. 1 No. 2. 92-101. 